\title{
PMSM Sliding Mode Control Based on a Reaching law
}

\author{
Guixi Jia Hongda Zhang Hongchao Dong Jinbo Guo \\ School of Electrical Engineering and Automation \\ Tianjin University \\ Tianjin, China \\ e-mail: zhanghongda2014@163.com
}

\begin{abstract}
The speed loop of the AC servo system used to apply PI control method, it makes the system vulnerable to the volatile motor parameters and load disturbances. Sliding mode control(SMC) has successfully overcome the above-mentioned defects of PI control method and is expected to be widely used in high-performance servo systems. The $i_{d}=0$ control method is adopted in this paper and a reaching law sliding mode controller is designed on this basis. Then the PI control method frequently applied in speed loop is replaced by this SMC controller and the feasibility and superiority are tested through simulation results in the end.
\end{abstract}

Keywords-permanent magnet sychronous motor(PMSM); vector control; sliding mode control(SMC); reaching law

\section{INTRODUCTION}

In the wake of rapid development of PMSM, the DC speed regulating system was gradually replaced by the AC one. An AC speed regulating system consists of position loop, speed loop and current loop. Typically, the inner speed loop adopts PI control method, which is unsuitable when fast response is needed by the system[1]. Originated in 1950s, sliding model control is a kind of discontinuous nonlinear control in itself, by constantly regulating the system structure, it can be perfectly applied in AC speed regulating system which is featured by changeable parameters and constant load disturbance. Sliding mode control system has multiple advantages as insensibility to system parameters and load disturbance, fast response and simple application[2].

\section{MATHEMATICAL MODEL OF PMSM}

Vector diagram of PMSM is shown in Fig.1, to simplify analysis, this article makes the following assumptions: (1) the three-phase winding of the stator is symmetric. (2) Ignoring the influence of magnetic saturation, eddy current and hysteresis loss. Presuming the magnetic circuit of the motor is linear. (3) Induced electromotive force of the stator and air gap magnetomotive force are sinusoidal. (4) Ignoring damper windings. Under such assumptions, the basic equation of voltage and flux of PMSM in $d, q, 0$ coordinate can be described by (1) and (2).

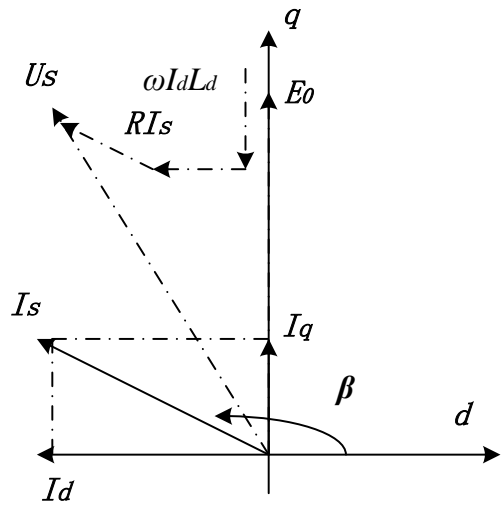

Figure 1. Vector diagram of PMSM.

$$
\begin{gathered}
\left\{\begin{array}{l}
u_{d}=\frac{d \psi_{d}}{d t}+R_{s} i_{d}-\omega \psi_{q} \\
u_{q}=\frac{d \psi_{q}}{d t}+R_{s} i_{q}+\omega \psi_{d}
\end{array}\right. \\
\left\{\begin{array}{c}
\psi_{d}=L_{d} i_{d}+\psi_{f} \\
\psi_{q}=L_{q} i_{q}
\end{array}\right.
\end{gathered}
$$

The torque equation is:

$$
\begin{gathered}
T_{e}=P_{n}\left[\psi_{f} i_{q}+\left(L_{d}-L_{q}\right) i_{d} i_{q}\right] \\
T_{e}-T_{L}=\frac{J}{P_{n}} \frac{d \omega}{d t}
\end{gathered}
$$

In the equation, $L_{d}, L_{q}$ are $\mathrm{d}$ axis synchronous inductances and $\mathrm{q}$ axis synchronous inductances, respectively; $R_{S}$ is stator resistance; $P_{n}$ is pole pair number of the stator winding; $i_{d}, i_{q}$ are the $\mathrm{d}$ and $\mathrm{q}$ axis current in $d 、 q$, o coordinates, respectively. Thus it can be seen that the mathematical model of the PMSM is simplified quite a deal by being changed from variable coefficient differential equation to constant-coefficient equations. 


\section{DESIGN OF SLIDING MODE CONTROLLER}

\section{A. THEORY of SLIDING MODE CONTROL}

The advantages of the SMC are (1) the control law is easy to design; (2) it's insensitive to the system parameters, in this case, the control system has a relatively fast response and self-adjustment when disturbance occurs, thus improving the robustness of the system. However, when the state track of the system reaches the sliding surface $s$, oscillation is inevitable, and this contributes the primary defect of the existing SMC[3].

When designing the sliding mode controller, the existence, accessibility and stability of the sliding mode should be taken into consideration. Besides, the dynamic quality of the sliding mode is noticeable. During the control process, the condition of accessibility $s \dot{s}<0$ should be met. The design method based on reaching law can be adopted to improve the dynamic quality. The exponential approach law takes the following form:

$$
\dot{s}=-\varepsilon \operatorname{sgn}(s)-k s
$$

$\varepsilon 、 k$ are positive constants. The sliding surface $\mathrm{s}=0$ can be reached within limited time through exponential approach law. Response speed can be enhanced by increasing $k$ moderately[4]. The state point of the system reaches the surface with the speed of $|\varepsilon|$, therefore, the speed can be decreased by reducing $\varepsilon$, and thus reducing oscillation.

\section{B. DESIGN of SMC CONTROLLER of SPEED LOOP}

Defining the state variable of the PMSM speed control system $x_{1}, x_{2}$

$$
\left\{\begin{array}{c}
x_{1}=\omega^{*}-\omega \\
x_{2}=\dot{x}_{1}=-\dot{\omega}
\end{array}\right.
$$

Where $\omega^{*}$ is the speed reference produced by the controller of the position loop. $\omega$ is the rotational speed of rotor. The input signal of speed loop is produced by comparing speed reference and real speed. Equation (7) is obtained based on (4) and (6).

$$
\left\{\begin{array}{c}
\dot{x}_{1}=-\dot{\omega}=\frac{P_{n}}{J}\left(T_{L}-\frac{3 P_{n} \psi_{f} i_{q}}{2}\right) \\
\dot{x}_{2}=-\ddot{\omega}=-\frac{3 P_{n}^{2} \psi_{f} \dot{i}_{q}}{2 J}
\end{array}\right.
$$

Defining $X=\frac{3 P_{n}^{2} \psi_{f}}{2 J}, \quad Y=\frac{P_{n} T}{J}, Z=i_{q}$, then (7) can be changed into (8) and (9).

$$
\left\{\begin{array}{l}
\dot{x}_{1}=-\dot{\omega}=Y-X \\
\dot{x}_{2}=-\ddot{\omega}=-X Z
\end{array}\right.
$$

$$
\left[\begin{array}{l}
\dot{x}_{1} \\
\dot{x}_{2}
\end{array}\right]=\left[\begin{array}{ll}
0 & 1 \\
0 & 0
\end{array}\right]\left[\begin{array}{l}
x_{1} \\
x_{2}
\end{array}\right]-\left[\begin{array}{l}
0 \\
X
\end{array}\right] I
$$

Defining the sliding surface and take partial derivative:

$$
\dot{s}=c \dot{x}_{1}+\dot{x}_{2}
$$

Combining (5) and (9)

$$
\dot{s}=c x_{2}-X I=-\varepsilon \operatorname{sgn}(s)-k s
$$

Therefore, the control variable $i_{q}$ can be obtained:

$$
i_{q}=\frac{1}{X} \int\left(c x_{2}+\varepsilon \operatorname{sgn}(s)+k s\right) d t
$$

Control variable $i_{q}$ is taken as given $\mathrm{q}$ axis current for inner current loop.

\section{STABILITY TEST}

The conditions of accessibility and stability should be met during the control process. Constructing lyapunov function $V=0.5 s^{2}$, according to lyapunov stability theory, the condition of stability of SMC is $\lim _{s \rightarrow 0} s \dot{s}<0$, according to (5):

$$
s \dot{s}=-s(\varepsilon \operatorname{sgn}(s)+k s)
$$

Since $\mathrm{k}$ and $\varepsilon$ are positive constants, when $\mathrm{s}$ is positive, the minus ahead guarantees that (13) is negative, and when $s$ is negative, the switching function is negative, (13) remains negative. Therefore, the conditions of accessibility and stability are met. The sliding surface $s=0$ can be reached within limited time and the system is tested to be stable under SMC based on exponential approach law.

\section{SIMULATION RESULTS}

The article adopts $i_{d}=0$ vector control method, the vector control system of PMSM speed control system is shown in Fig.2. Its simulation model is built in SIMULINK. The system consists of speed loop controller, current loop controller, Park and Clark transformation, SVPWM modulation, inverter and Park inverse transformation, etc. Fig. 3 shows speed and current loop model.

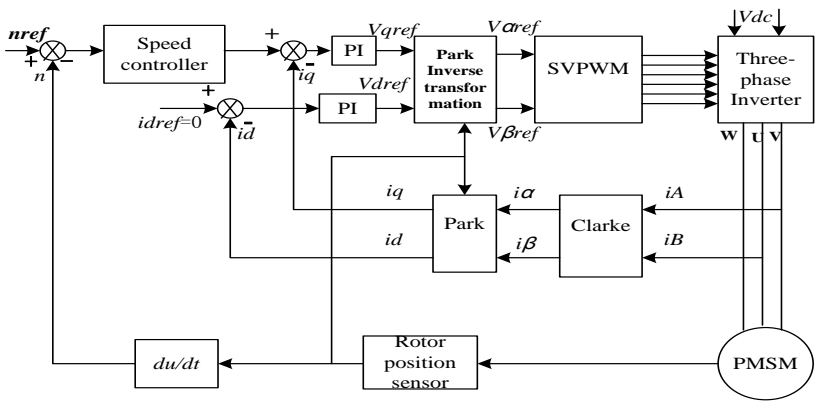

Figure 2. Vector control system of PMSM speed control system 


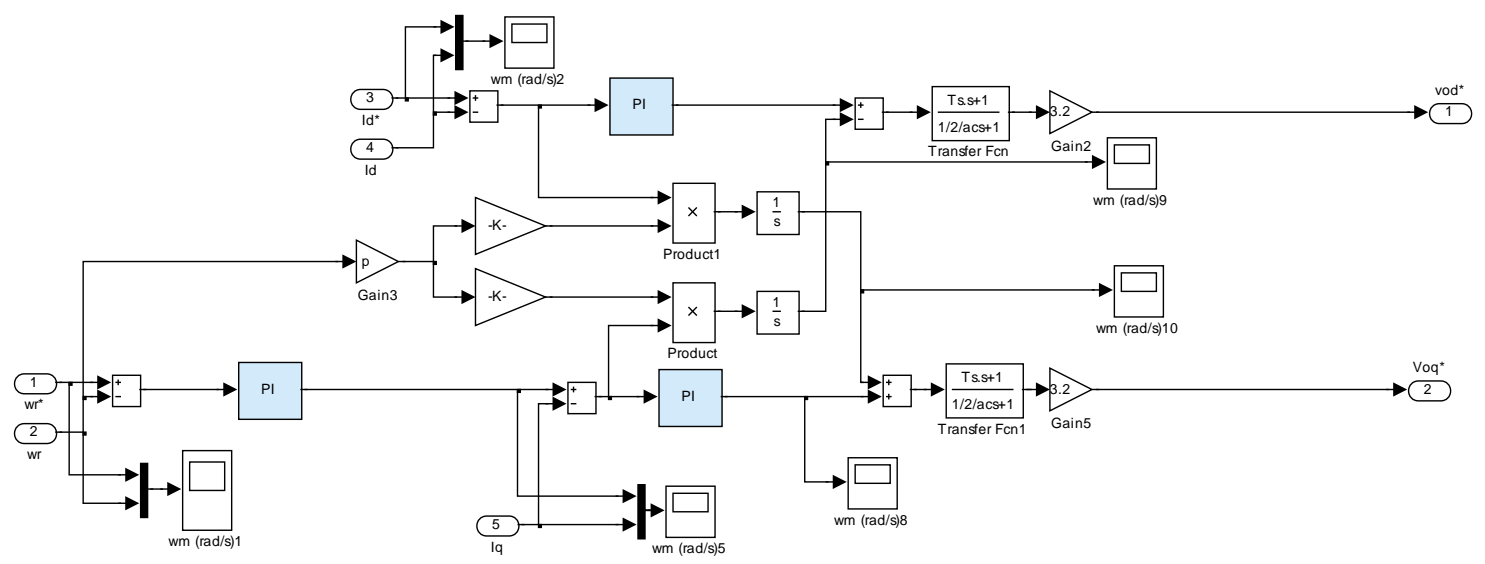

Figure 3. Speed loop and current loop model

$\omega r$ is feedback rotation speed and speed reference $\omega r^{*}$ is produced by position loop. The difference of the two signals is taken as input of speed controller, which adopts PI control method. The parameters of PMSM are set as follows, rated power is $10 \mathrm{kw}$, rated line voltage $\mathrm{U}=380$ volts, frequency 30 hertz, number of pole pairs $\mathrm{P}=12$, stator resistance $R=1.25 \Omega$, $\mathrm{d}, \quad \mathrm{q}$ axis inductance $L_{d}=0.006 \mathrm{H}, \mathrm{q}$ axis inductance $L_{q}=0.019 \mathrm{H}$, friction coefficient $B=0.191$, rotational inertia $J=3.74$ and flux of main pole $\Phi_{f}=1.337$. Load torque is $100 \mathrm{~N} * \mathrm{~m}$ and speed reference is $100 \mathrm{r} / \mathrm{min}$. When the speed loop adopts traditional PI control method, the simulation results of speed response, three-phase current and torque response curves are shown in Fig.4, Fig.5 and Fig.6 respectively.

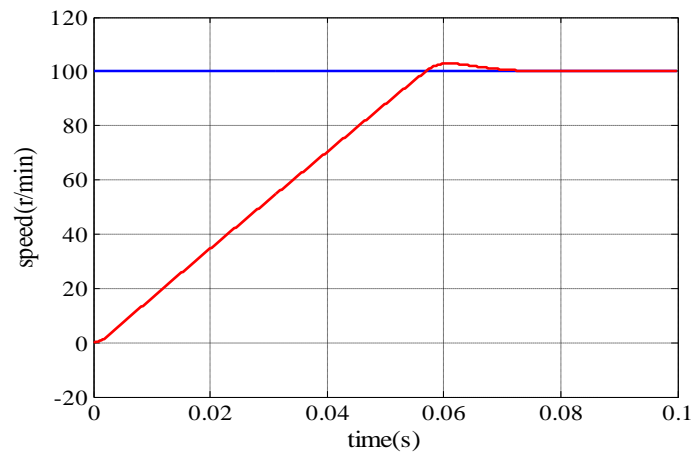

Figure 4. Speed response curve

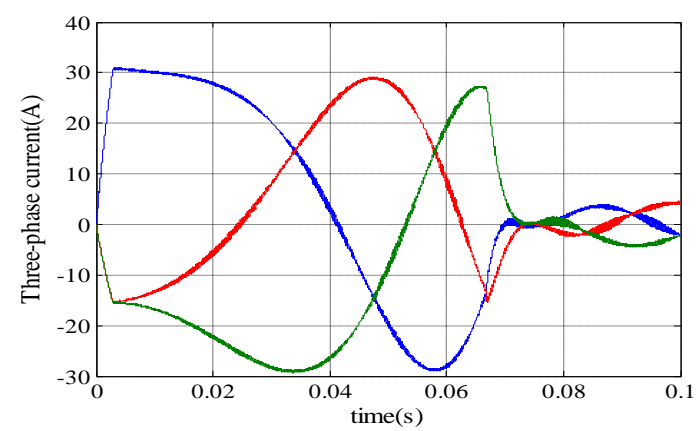

Figure 5. Three-phase current response curve

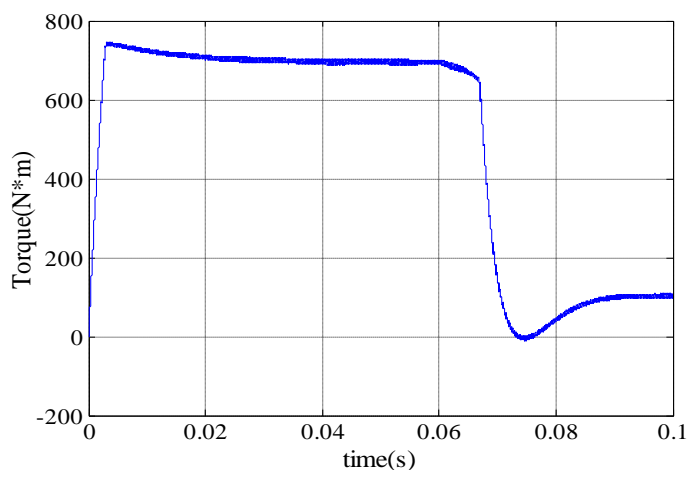

Figure 6. Torque response curve

Notably, the real speed catches the speed reference at $0.075 \mathrm{~s}$, but oscillation and overshoot exist, Three-phase current shows serious distortion and torque jump occurs at $0.065 \mathrm{~s}$. Then replacing PI controller by SMC controller based on exponential approach law, whose model is shown in Fig.10. Speed, three-phase current and torque response curves are shown in Fig.7, Fig.8 and Fig.9, respectively. Under this new controller, the speed response curve is free from overshoot with shorter time to catch the speed reference, Three-phase current shows little distortion and torque response decrease to 100 in a smooth manner without jump.

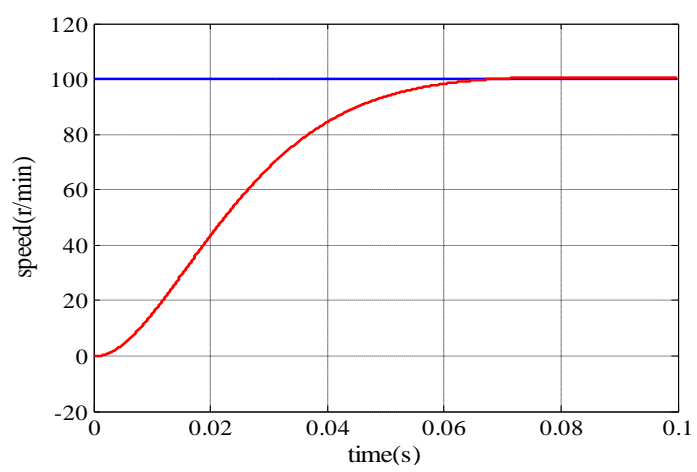

Figure 7. Speed response curve 


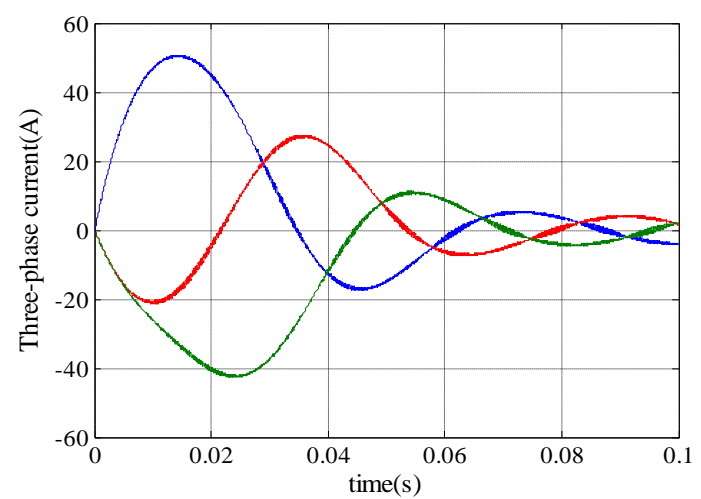

Figure 8. Three-phase current response curve

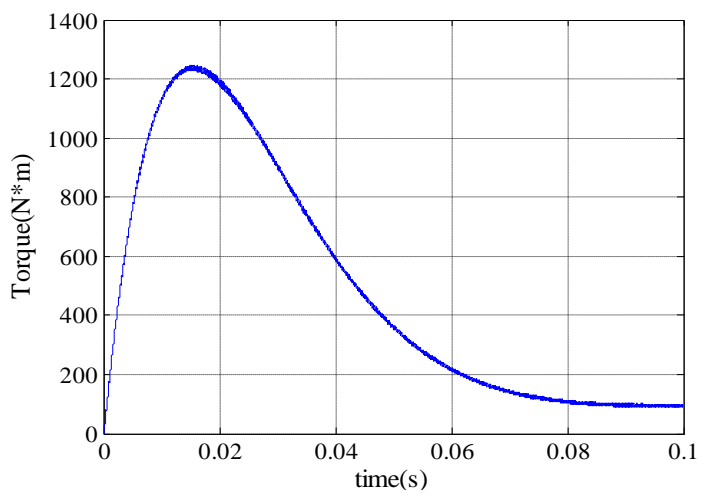

Figure 9. Torque response curve

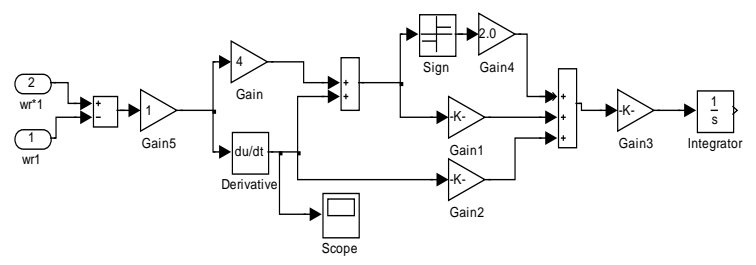

Figure 10. Model of SMC controller based on exponential approach law

Increasing load torque to $T_{L}=300 \mathrm{~N} * \mathrm{~m}$ abruptly at $0.1 \mathrm{~s}$ with other parameters remaining unchanged, the torque response under PI controller and SMC controller are shown in Fig. 11 and Fig.12.

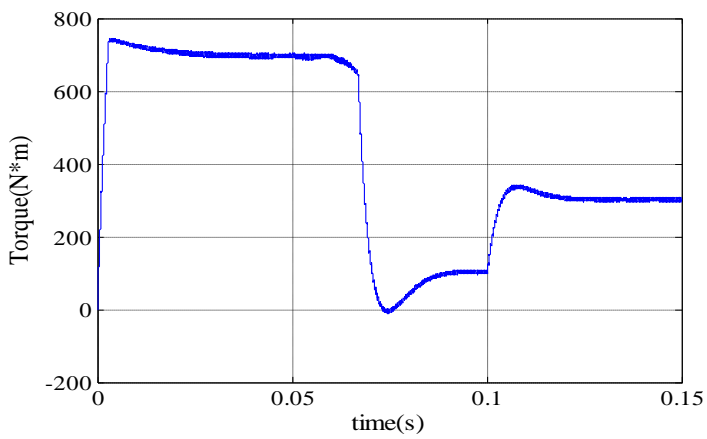

Figure 11. Torque response curve under abrupt increase of load

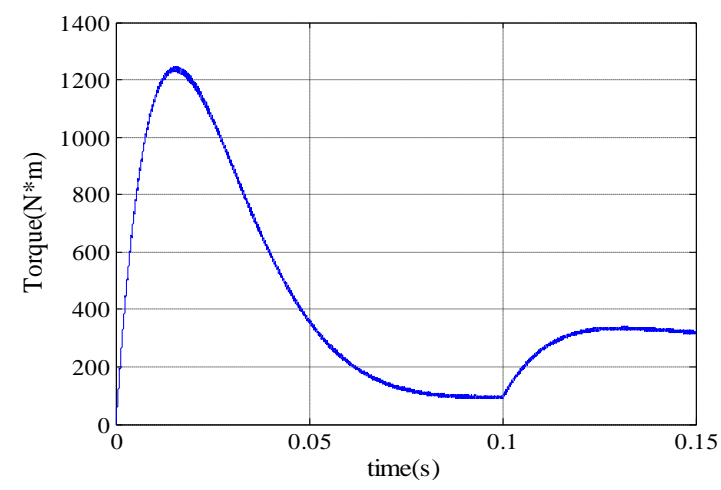

Figure 12. Torque response curve under abrupt increase of load of SMC

\section{CONCLUSIONS}

This article has designed speed loop controller of the speed control system through SMC based on exponential approach law, given a theoretical analysis of its stability and feasibility and built models on SIMULINK platform. By comparing the simulation results, it is tested that SMC is not only applicable in PMSM speed control system, but also can improve the dynamic and static performance of the system, thus realizing fast and non-overshoot speed tracking.

\section{REFERENCES}

[1] Zhang Changfan, Wang Yaonan, He Jing. Variable structure intelligent control for PM synchronous servo motor drive[J]. Proceedings of the CSEE,2002,22(7):13-17.

[2] Tian Yanfeng, Guo Qingding. Sliding-mode-H robustness tracking control for permanent magnet[J]. Transactions of China Electrotechnical Society,2004,19(4):2-5.

[3] Ge Baoming, Zhao Nan. DSP-based discrete-time reaching law control of switched reluctance motor[C]. Power Electronics and Motion Control Conference, $2006: 1-5$.

[4] Ge Baoming, Zheng Qionglin, Jiang Jingping, PM Synchronous Motor Drive Based On Discrete-Time Reaching Law And Internal Model Controls[J], Proceedings of the CSEE.2004 24(11).

[5] Jia Hongping, He Yikang. Variable structure sliding mode control for PMSM DTC $[J]$. Transactions of China Electrotechnical Society,2006,21(1):1-6.

[6] Edward Y. Y. Ho and Paresh C. sen. Control Dynamics of Speed Drive System Using Sliding Mode Controllers With Integral Compensation[J]. IEEE 1991, $27: 883 \sim 892$. 